\title{
Thermal load non-uniformity estimation for superheater tube bundle damage evaluation
}

\author{
Martin $\mathrm{Nad}^{1,{ }^{1}, \text {, Zdeněk Jegla }}{ }^{1}$, Tomáš Létal ${ }^{1}$, Pavel Lošák ${ }^{1}$, Jiři Buzík ${ }^{1}$ \\ ${ }^{1}$ Brno University of Technology, Faculty of Mechanical Engineering, Technická 2896/2, \\ 61669 Brno, Czech Republic
}

\begin{abstract}
Industrial boiler damage is a common phenomenon encountered in boiler operation which usually lasts several decades. Since boiler shutdown may be required because of localized failures, it is crucial to predict the most vulnerable parts. If damage occurs, it is necessary to perform root cause analysis and devise corrective measures (repairs, design modifications, etc.). Boiler tube bundles, such as those in superheaters, preheaters and reheaters, are the most exposed and often the most damaged boiler parts. Both short-term and long-term overheating are common causes of tube failures. In these cases, the design temperatures are exceeded, which often results in decrease of remaining creep life. Advanced models for damage evaluation require temperature history, which is available only in rare cases when it has been measured and recorded for the whole service life. However, in most cases it is necessary to estimate the temperature history from available operation history data (inlet and outlet pressures and temperatures etc.). The task may be very challenging because of the combination of complex flow behaviour in the flue gas domain and heat transfer phenomena. This paper focuses on estimating thermal load nonuniformity on superheater tubes via Computational Fluid Dynamics (CFD) simulation of flue gas flow including heat transfer within the domain consisting of a furnace and a part of the first stage of the boiler.
\end{abstract}

Keywords: boiler damage, superheater tubes, thermal load non-uniformity, Computational Fluid Dynamics (CFD)

\section{Introduction}

Boiler can be described as a device which produces steam (or in some cases hot water) using heat received from chemical reaction. Choice of the main boiler components depends on fuel type which is burnt and the boiler size is based on required amount of steam production for consequent use in turbine or other processes. There are three basic types of fuels which are usually burnt: gas (natural gas, methane...), liquid (various oils) and solid (dark and brown coal ...). Important distinction between various fuels is in their flue gas composition, since gas burning produces almost no ash in comparison with liquid and solid fuels that produce a lot of ash, often resulting in significant problems [1, 2].

\footnotetext{
*Corresponding author: nad@fme.vutbr.cz

Reviewers: Ján Vávro, Juraj Grenčík
} 
Nowadays, the most desired features of boilers are high efficiency, reliability as well as optimal fuel and operation flexibility. Therefore, demand for boilers with higher standards, higher efficiency and possibility of burning various fuel types, but also with lower impact on the environment, is more relevant than ever.

\subsection{Boiler damage types}

During the boiler service life (often more than 200000 hours), some kind of damage is basically unavoidable. Each damage type is unique with different impact, severity and influence on service life. Although various mechanisms of damage often act together, they can be divided into five basic categories based on damage root cause [3-5]:

- Temperature (Creep, Long-term and Short-term overheating)

- Corrosion (waterside, fireside)

- Flow-related (erosion, cavitation, fouling, slagging)

- Operation (change of fuel, incorrect regulation, sudden load change...)

- Construction (improper equipment design, material misuse...)

Tubes with internal pressure are crucial parts of water tube boilers as well as steam generators. They are often exposed to high temperatures and pressures both on steam side as well as flue gas side. High sensitivity of material properties to temperature at these conditions combined with imperfect design methods increase the probability of unexpected high temperature damage. The tube temperature may rise during operation time due to oxide scales growth (from inside or outside) or because of reduction of flow rate of "coolant" in the tubes. Service life of tubes is limited by effects of high temperature, stresses, aggressive environment, corrosion degradation and other. Resistance can be increased by proper material selection [6].

\subsection{Temperature related damage}

Damage due to high temperature is common problem of tube bundles located in boilers. Temperature may cause material overheating as well as creep or in combination with aggressive flue gasses also high temperature corrosion. Investigation of damage caused by overheating requires detail analysis of damaged components consisting of microstructure analysis and identification of other forms of material degradation caused by high temperature. It is useful to distinguish short-term and long-term overheating as they lead to different types of damage.

\subsubsection{Short-term overheating}

It occurs if tube material temperature rises rapidly above designed values, generally for a short time. Short-term overheating can be divided into three types [3]:

- Subcritical (material temperature under the lower critical transformation temperature $727^{\circ} \mathrm{C}$ for carbon steel)

- Intercritical (material temperature between the lower and higher critical transformation temperature)

- Upper critical (material temperature above the upper critical transformation temperature $-843{ }^{\circ} \mathrm{C}$ for carbon steel)

Metal yield strength is reduced at elevated temperatures and may be exceeded by stresses, leading to plastic deformation, often in form of bulking which leads to thinner walls and later to rupture of the tube wall. Higher temperatures and stresses may also cause rupture of 
the tube due to exceeding of tensile strength. In case of extremely high temperatures, short term creep may occur, during which time to damage decreases with increasing temperature. The main cause of short term overheating is lack of coolant flow, often connected with oxide scales, corrosion, fouling or slagging. Therefore, it is necessary to monitor coolant flow and the state of the pipes [3].

\subsubsection{Long-term overheating}

It occurs if the designed material temperature is exceeded for days, weeks, months or even longer. Long-term overheating is the most common root cause of boiler damage with $90 \%$ of cases affecting preheaters. It is result of combination of temperature, time, stress and material properties. Long-term overheating, often combined with creep, may result in tube rupture. Therefore, proper material selection and operational conditions are required to prevent this kind of damage.

\subsubsection{Prevention of temperature damage}

Overheating is common type of damage mainly of components, such as boiler tube bundles, located in areas with high flue gas temperature. Tube degradation due to overheating rises with rising temperature, stress and time. Improper combination of these factors may cause damage and failure. According to standards, influence of temperature is reflected in maximal allowable stress value (decreases with increasing temperature), during design of boilers and pressure vessels. The most common material in boilers is carbon steel, because of its price. However, this material is often not sufficient for higher temperatures. Therefore, tubes exposed to steam are usually made of low alloyed steel used with small amount of molybdenum (normally $0.25-1.25 \%$ for better creep resistance) and chrome (normally $0.5-2.5 \%$ for better creep resistance and slowing down of high temperature corrosion). $[1,3]$

\section{Equipment description}

This article focuses on three-staged boiler with natural circulation and steam production $60 \mathrm{t} / \mathrm{hr}$, located in a chemical plant. Several fuel types were burnt in this boiler during the service life, however it was primarily designed for natural gas, heavy fuel oil and tar mixtures.

Boiler has several crucial parts (see Fig. 1). For various types of fuel combustion, four low emission burners are used. Combined with flue gas regulation system, they were selected to reduce NOx emissions in order to meet legislation limits. Membrane walls of combustion chamber (first stage) and of second stage work as evaporators. Two superheaters (P1 and P2) and one economiser are located in the second stage, second economiser is located in the third stage.

\subsection{Boiler parameters}

There are several parameters which are important during boiler damage analysis. One of them is boiler service time, which is in this case $62000 \mathrm{hrs}$ (at the time of experimental data collection). Other boiler parameters can be divided into two basic categories (all parameters are for natural gas combustion): 
a) Design parameters:

- Steam production: $60 \mathrm{t} / \mathrm{hr}$

- Superheated steam temperature: $375^{\circ} \mathrm{C}\left(+23{ }^{\circ} \mathrm{C},-10^{\circ} \mathrm{C}\right)$

- Superheated steam pressure: $3.82 \mathrm{MPa}$

- Feed water temperature: $145^{\circ} \mathrm{C}$

b) Real parameters during natural gas combustion

- Steam production: $35-95 \mathrm{t} / \mathrm{hr}$

- Superheated steam temperature: $340-385^{\circ} \mathrm{C}$

- Superheated steam pressure: $3.45-3.65 \mathrm{MPa}$

Apparently, the design parameters differ from the actual operation parameters, so they should not be used for proper damage estimation. It is common that there is not enough data history with required parameters, too. Therefor it is necessary to obtain them by further calculations.

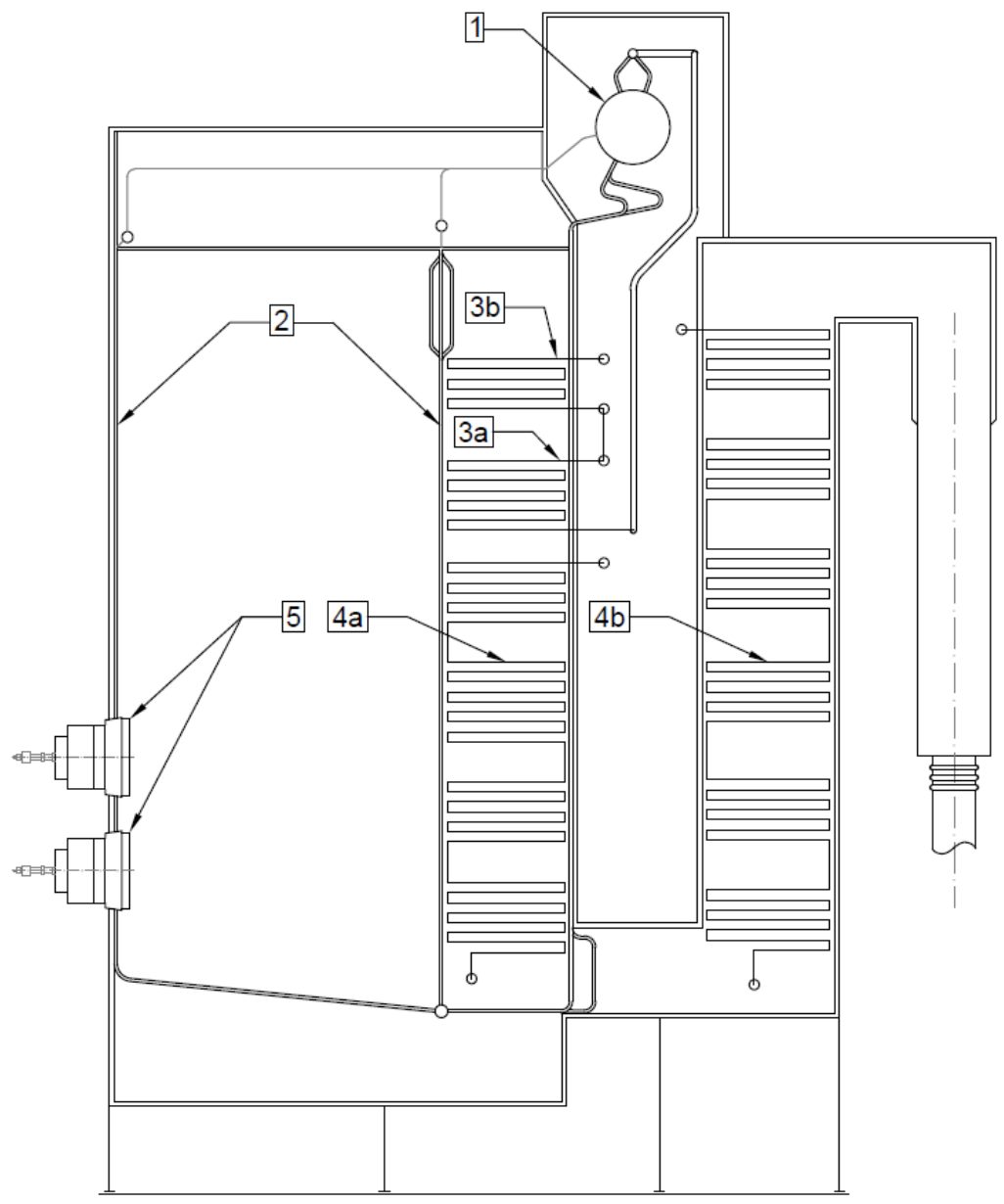

Fig. 1. Simplified boiler scheme (1 - boiler drum, 2 - evaporator/membrane walls, $3 \mathrm{a}-$ superheater P1, 3b - superheater P2, 4a - economizer E1, 4b - economizer E2, 5 - burners) 


\subsection{Superheater P2}

Superheaters are generally the most damaged parts of boiler since they are located in rough areas of boiler, often exposed to high temperatures and pressures. Various types of damage may occur however temperature related are the most common.

Steam superheating in the examined boiler is realized by two horizontal superheaters (P1 and P2, see Fig. 1 pos. 3a and 3b). Both superheaters are in form of tube bundles located in second stage of boiler. This article focuses on superheater P2 (see Fig. 2) which is the most exposed one as first one after combustion chamber. It is located at the top of the second stage (at $19.31 \mathrm{~m}$ elevation) and is made of 66 tubes in 3 rows (198 tubes total).
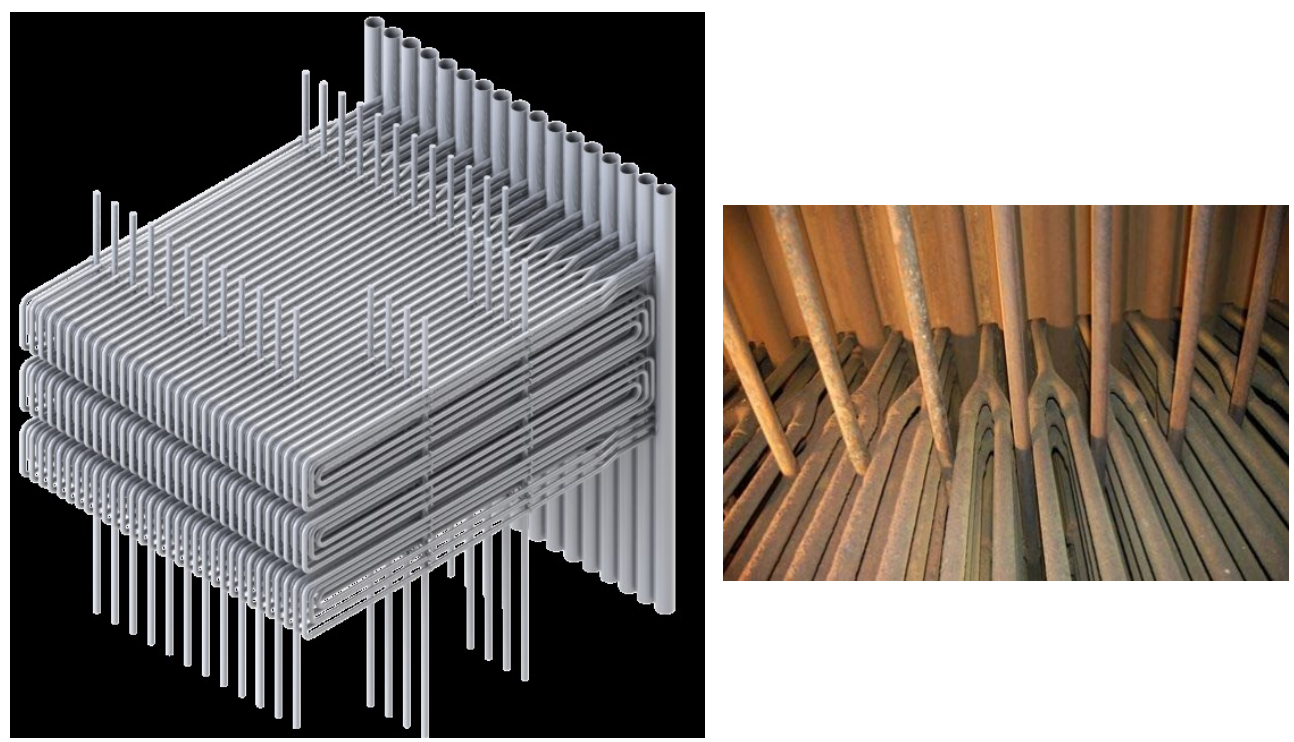

Fig. 2. Superheater a) partial 3D model (left), b) photo (right)

\section{Thermal load non-uniformity simulation}

To estimate temperature related damage, it is necessary to know tube surface temperatures. However, this information is not available in most cases, therefore it is necessary to estimate thermal load from key information which are measured during operation.

Combination of several approaches was used (typically combination of analytical calculations, thermal-hydraulic calculations and computational fluid dynamics (CFD) calculations for flue gas flow simulations). All simulations are performed using experimental data received during combustion of natural gas. However, several presuppositions of unknown conditions were used. One of them is optimal blowing frequency that provides clean tube surface without impurities.

\subsection{Temperature field on superheater tubes}

First of all, control thermal-hydraulic calculations were performed to obtain surface temperatures of the superheater P2 tubes. Commercial software was used, however, few simplifications, related to superheater geometry, had to be made since the software was able to simulate only average steam/flue gas flows through tube bundle, however for our case, it 
was sufficient. During surface temperature calculation, tubes were divided into ten identical subsections (294 $\mathrm{mm}$ each). As a basic input parameters, experimental data were used:

- Flue gas temperature after combustion chamber: $734{ }^{\circ} \mathrm{C}$

- Flue gas velocity after combustion chamber: $17.8 \mathrm{~m} / \mathrm{s}$

- Steam input temperature: $248.2{ }^{\circ} \mathrm{C}$

- Steam input velocity: $14.7 \mathrm{~m} / \mathrm{s}$

In order to obtain relevant results compared to experimental data, it was necessary to include the influence of oxide scales (see Fig. 2b), which were created during operation and had influence on thermal duty. It was performed by simulating fouling using the fouling coefficient $\mathrm{R}_{\mathrm{z}}=0.0035 \mathrm{~m}^{2} \cdot \mathrm{K} / \mathrm{W}$. To verify the results accuracy, outlet steam temperature was compared to experimental data $\left(369^{\circ} \mathrm{C}\right)$. Results in form of surface temperatures (with and without influence of oxide scales) are shown on Fig. 3.

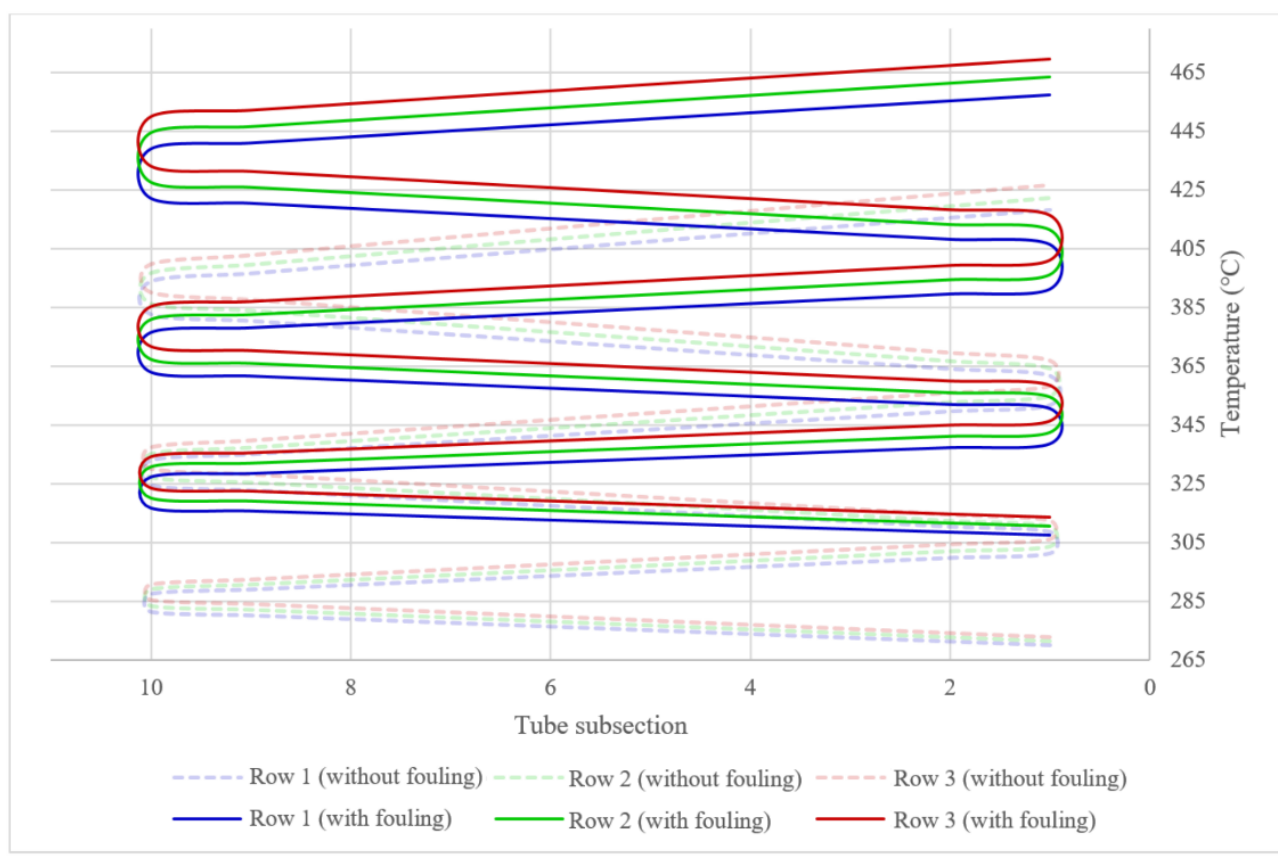

Fig. 3. Surface temperatures on tube rows of superheater P2 with and without fouling (simulation of oxide scales)

The graph shows great influence of oxide scales (simulated using fouling coefficient) on tube surface temperature. Those temperature differences are in range from $35.3{ }^{\circ} \mathrm{C}$ to $50.2{ }^{\circ} \mathrm{C}$. The average temperature difference is $42{ }^{\circ} \mathrm{C}$ - that is high enough to have significant influence on thermal duty as well as temperature related damage resistance. Because of that, further simulations were necessary.

\subsection{Flue gas boiler flow}

To obtain accurate surface temperatures on all tubes, it is necessary to know thermal load first. Thus, CFD analyses were performed to simulate flue gas flow in the boiler. Combustion was not simulated, as it would presumably have just a little effect on the results in the area of interest, which is located next to the combustion chamber and encompasses the superheater. 
During basic hot flue gas simulation simplifications were used:

- Model size. Simulation of combustion chamber and part of second stage.

- Model geometry. Membrane walls were replaced by smooth walls with thickness of $5 \mathrm{~mm}$ simulating tube wall thickness. To simulate cooling by membrane walls, wall emissivity was set up to simulate oxide scales (influencing thermal flow). Also, wall temperature, based on location in combustion chamber, was calculated using heat balance calculations.

- Tube bundles geometry. Superheater was simulated as a porous zone, as well as tubular grid between combustion chamber and second stage was simulated as porous jump, both to cover influence of local resistance

- Combustion process. Flow of hot flue gases was simulated as well as their cooling. Parameters of flue gases were used based on experimental data received. Burners were modelled as four inlets with diameter of $1 \mathrm{~m}$. Inlet flue gas temperature $\left(1569^{\circ} \mathrm{C}\right)$ had to be calculated based on heat balance of boiler, because measured flame temperature would not properly represent the fluid gas temperature.

- Other CFD setup. For turbulence simulation, K- $\varepsilon$ turbulence model with scalable wall functions was used. Radiation was simulated after stabilization of calculation and Discrete Ordinates model was used. Fluid properties of exact flue gas composition were used. Absorption coefficient was calculated by UDF, and its value varied based on position and local temperature (average value was $0.15451 / \mathrm{m}$ ). Simulation was computed as steady-state and equation discretization of second order upwind scheme was used.

\subsection{Temperature load non-uniformity}

To evaluate heat load non-uniformity on superheater, it is necessary to know flue gas temperatures and velocities in plane directly above superheater. As can be seen on Fig. 4, velocities in this plane are not homogenous, with average of $4.9 \mathrm{~m} / \mathrm{s}$. Those differences are caused by insufficient flow stabilization after turn in the upper part of the second stage. 

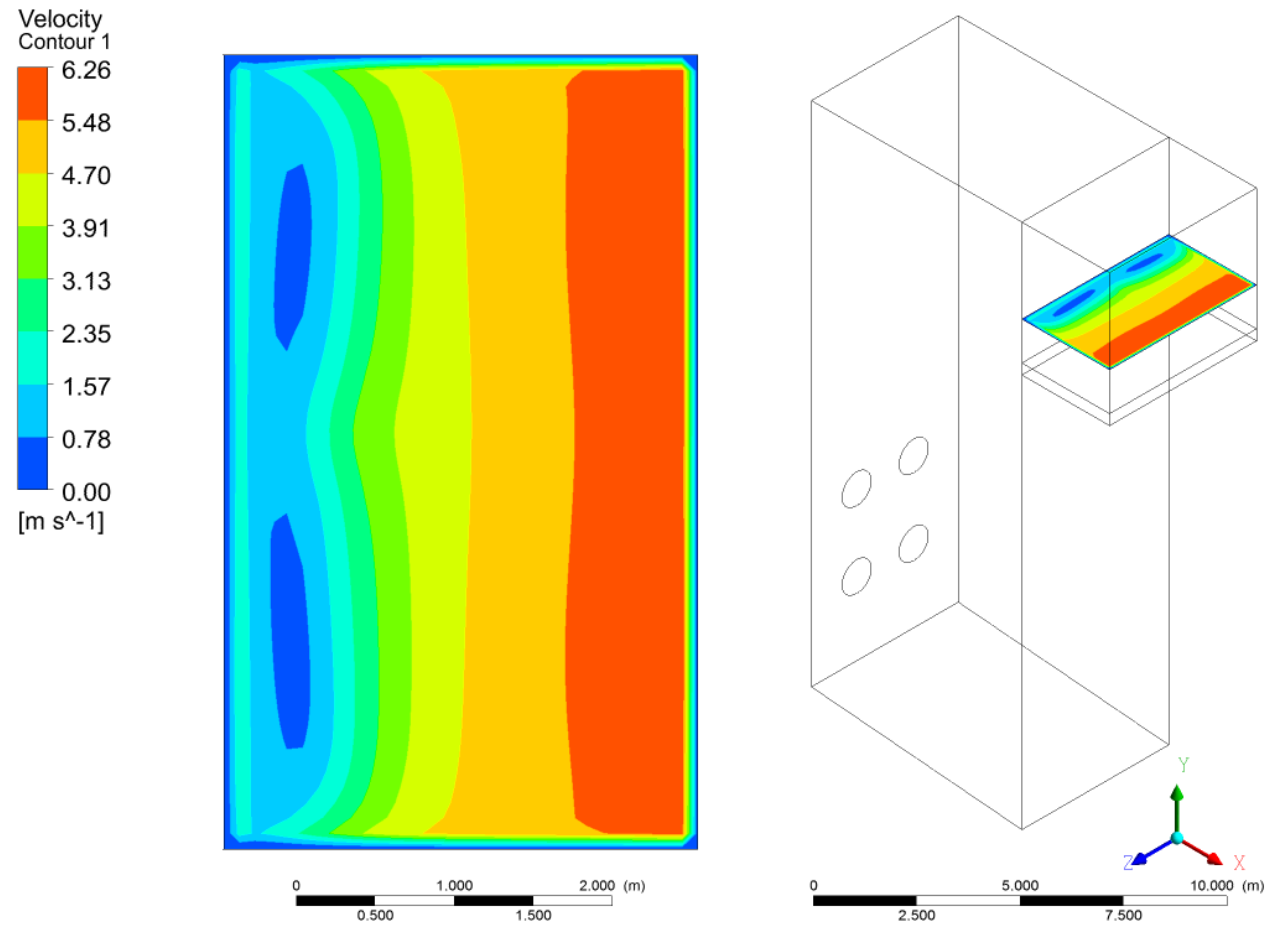

Fig. 4. Flue gas velocity above superheater P2.

Uneven flue gas flow also strongly effects the temperature distribution, as can be seen in Fig. 5. Flue gas streams with higher velocity have shorter residence time in combustion chamber and they do not have enough time to transmit heat into evaporator (the membrane walls). On the other hand, slower flue gas streams have enough time to get cooler. Average temperature in plane above superheater is $683.1^{\circ} \mathrm{C}$. 

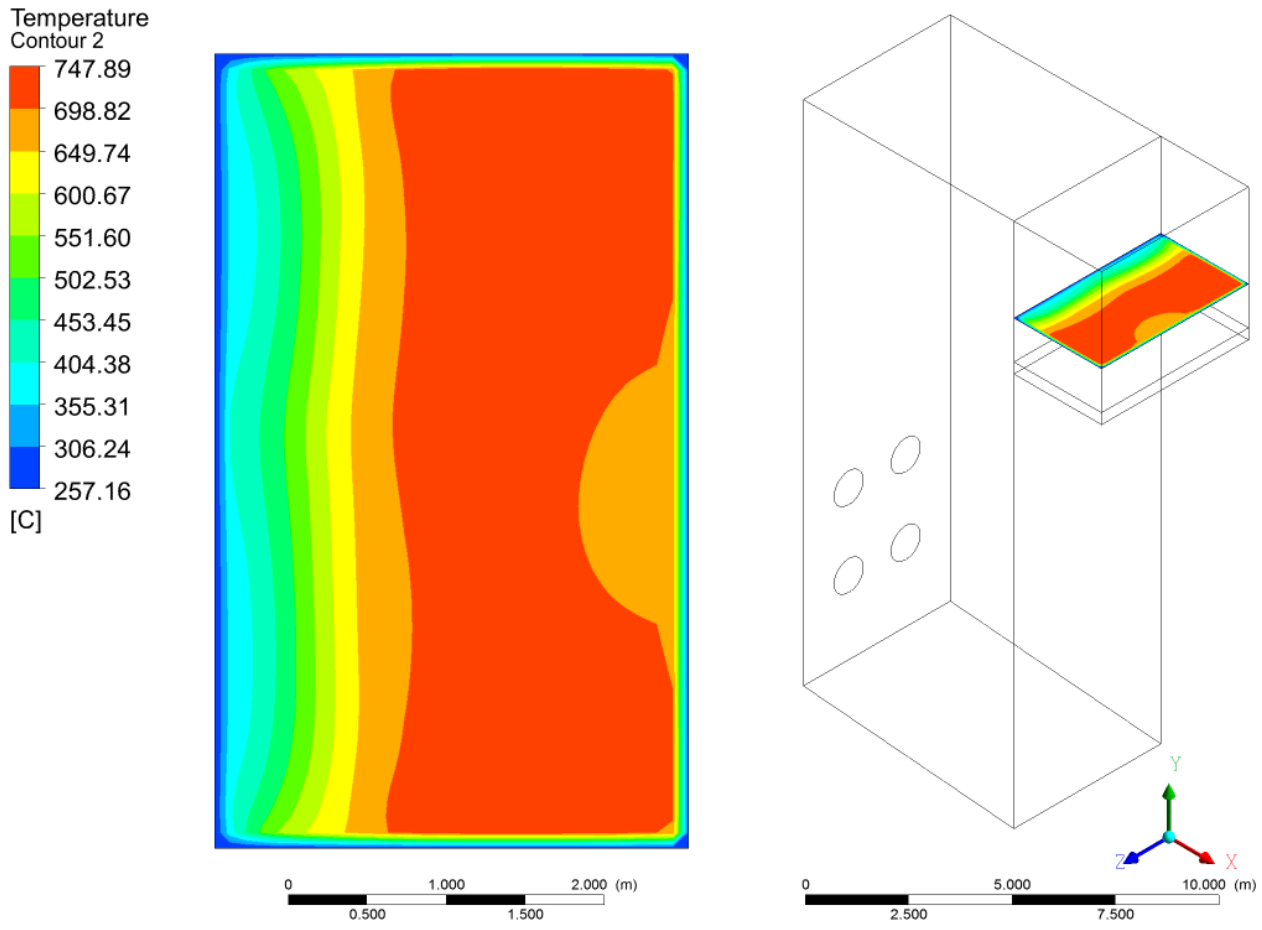

Fig. 5. Flue gas temperature above superheater $\mathrm{P} 2$.

Uneven flue gas velocities and temperatures pointed out problems with measuring of those parameters. Measured value is strongly dependent on location where the sensor is located.

\section{Conclusion}

Temperature related damage is a common damage type related to boilers. Superheaters are among the most influenced equipment. This article focuses on particular superheater as a part of steam boiler located in chemical plant. To consider damage importance, it is necessary to know surface temperatures of the superheater tubes. Data provided by operators often do not include those temperatures. In order to calculate them, thermal load non-uniformity has to be known. It can be calculated by various approaches. In this article, thermal-hydraulic calculations combined with CFD analysis were used. Results showed, that velocity and temperature distribution in plane directly above superheater is not homogenous, therefore, significant local variations of tube damage can be expected.

The results of this project NETME CENTRE PLUS (LO1202) were co-funded by the Ministry of Education, Youth and Sports within the support programme „National Sustainability Programme I“.

\section{References}

1. K. Rayaprolu, Boilers: a practical reference [online]. Boca Raton, FL: CRC Press, [vid. 2017-03-20]. ISBN 978-1-4665-0054-9. http://dx.doi.org/10.1201/b12977 (2013)

2. J. L. Singer, Combustion: Fossil Power Systems. Windsor CT: Combustion Engineering, ISBN 978-0-9605974-0-6 (1981) 
3. D. J. Flynn, R. D. PORT, NALCO CHEMICAL COMPANY, ed. The nalco guide to boiler failure analysis. $2^{\text {nd }}$ ed. New York: McGraw-Hill, ISBN 978-0-07-174300-6 (2011)

4. X. Luo, Z. Zhang. Leakage Failure Analysis in a Power Plant Boiler. IERI Procedia [online] 5, International Conference on Agricultural and Natural Resources Engineering (ICANRE 2013), 107-111, ISSN 2212-6678 (2013)

5. M. Asgaryan, N. Simms, S. M. Wu. Prediction of the Remaining Service Life of Superheater and Reheater Tubes in Coal-Biomass Fired Power Plants. Advanced Materials Research [online] 856, 343-348, ISSN 1662-8985 (2014)

6. M. M. Rahman, J. Purbolaksono, J. Ahmad. Root cause failure analysis of a division wall superheater tube of a coal-fired power station. Engineering Failure Analysis [online] 17 (6), 1490-1494, ISSN 1350-6307, (2010) 